\title{
OPTIMASI FOIL NACA 63(3)018 PADA KAPAL HIDROFOIL MENGGUNAKAN PARTICLE SWARM (PSO)
}

\section{Eva Hertnacahyani Herrapraastanti ${ }^{1}$, Helmi Gunawan ${ }^{2}$, Eko Budi Santoso ${ }^{3}$}

\author{
1,2Teknik Mesin \\ Sekolah Tinggi Teknologi Ronggolawe Cepu, Indonesia \\ e-mail : 1ev.hertna@gmail.com, 2helmig85@gmail.com \\ ${ }^{3}$ Teknik Mesin \\ Politeknik SAKTI, Surabaya, Indonesia \\ e-mail : ${ }^{3}$ azizankoe@gmail.com
}

\begin{abstract}
Diterima: 19 September 2018. Disetujui : 3 Oktober 2018. Dipublikasikan : 10 Desember 2018
\begin{abstract}
ABSTRAK
Hidrofoil adalah sebuah kapal dengan bagian seperti sayap yang dipasang pada penyangga di bawah lambung kapal. Ketika kapal meningkatkan kecepatannya, hidrofoil memproduksi gaya angkat sehingga lambungnya terangkat dan keluar dari air. Ini menyebabkan pengurangan gesekan dan oleh karena itu peningkatan dalam kecepatan. Pemilihan foil menjadi salah satu aspek yang penting dalam meningkatkan prinsip kerja kapal (Suryadi, Arief, \& Amiadji, 2017). Geometri foil yang dirancang dalam penelitian ini diharapkan mampu menghasilkan gaya angkat (lift) yang maksimal serta menghasilkan gaya hambat (drag) seminimal mungkin pada waktu yang bersamaan. Sehingga nantinya geometri foil pada kapal hidrofoil tersebut adalah yang memiliki rasio koefisien gaya angkat $\left(C_{L}\right)$ terhadap koefisien gaya hambat $\left(C_{D}\right)$ paling besar $\left(C_{L} / C_{D}\right.$ maksimum). Selanjutnya proses optimasi menggunakan Particle Swarm Optimization (PSO) untuk mendapatkan nilai $C_{L} / C_{D}$ maksimum. Penelitian dilakukan melalui empat tahapan yaitu: (1) penentuan sudut serang dan Bilangan Reynold; (2) penentuan foil NACA 63(3)018; (3) iterasi dengan XFoil solver; (4) proses optimasi menggunakan GNU Octave 4.4.1. Hasil penelitian menunjukkan validasi pada MA409 menghasilkan nilai $C_{L}$ metode panel yang cukup baik dan akurat dengan rata-rata kesalahan sebesar $3.65 \%$, sedangkan validasi untuk $C_{D}$ rata-rata kesalahan $9.31 \%$. Hasil ini dalam toleransi yang diijinkan sesuai literatur (Reid, 2006) yaitu di bawah 9.5\%. Kesimpulan penelitian adalah nilai rasio gaya angkat terhadap gaya hambat $\left(C_{L} / C_{D}\right)$ maksimum dipengaruhi oleh bilangan Reynold. Semakin besar bilangan Reynold maka nilai $C_{L} / C_{D}$ maksimum juga semakin tinggi. Ketebalan (thickness) dan camber maksimum hidrofoil setelah dioptimasi mempunyai kecenderungan semakin meningkat dengan peningkatan bilangan Reynold.
\end{abstract}

Kata kunci: drag, lift, optimasi, particle swarm

\section{PENDAHULUAN}

Hidrofoil adalah sebuah kapal dengan bagian seperti sayap yang dipasang pada penyangga di bawah lambung kapal. Ketika kapal meningkatkan kecepatannya, hidrofoil memproduksi gaya angkat sehingga lambungnya terangkat dan keluar dari air. Ini menyebabkan pengurangan gesekan dan oleh karena itu peningkatan dalam kecepatan.

Pada saat meluncur dengan kecepatan rendah atau sedang, hidrofoil tampak seperti sebuah kapal konvensional yang badannya masuk ke dalam air. Namun, pada waktu meluncur dengan kecepatan tinggi, air akan membelok dari permukaan bagian atas foil, seperti udara membelok dari permukaan bagian atas pesawat terbang. Tekanan air pada permukaan foil atas menjadi menurun. Tekanan yang menurun ini dapat menimbulkan gaya angkat (lift). Bila semakin banyak gaya angkat yang ditimbulkan, bagian haluan kapal semakin muncul ke atas permukaan air. Akhirnya, seluruh lambung kapal naik dari permukaan air. Dengan demikian, kapal menjadi "bergantung pada foil". Bila kecepatan melambat, tekanan pada gaya angkat berkurang dan hidrofoil itu bergantung pada air. Pemilihan foil menjadi salah satu aspek yang penting dalam meningkatkan prinsip kerja kapal (Suryadi et al., 2017).

Foil yang dirancang dalam penelitian ini adalah tipe Naca 63(3)018 (Marzocca, 2017) yang nantinya diharapkan mampu menghasilkan gaya angkat (lift) yang maksimal dan pada saat yang bersamaan menghasilkan gaya hambat (drag) 
seminimal mungkin. Atau dengan kata lain, profil hidrofoil yang diinginkan adalah yang memiliki rasio koefisien gaya angkat $\left(C_{L}\right)$ terhadap koefisien gaya hambat $\left(C_{D}\right)$ atau $C_{L} / C_{D}$ maksimum.

Menurut Aji dalam (Suryadi et al., 2017), sudut serang divariasikan sebesar $10^{\circ}, 20^{\circ}$ dan $30^{\circ}$. Penelitian menghasilkan kesimpulan bahwa sudut serang terbaik berbeda-beda pada tiap kecepatan. Kecepatan 20 knot memiliki sudut serang hidrofoil terbaik sebesar $30^{\circ}$. Kecepatan 30 knot memiliki sudut serang hidrofoil terbaik sebesar $20^{\circ}$. Kecepatan 40 knot kapal sudah mencapai kondisi stall dimana kapal hidrofoil sudah kehilangan gaya angkat.

Khurana dan Sinha (Khurana, Winarto, \& Sinha, 2009) mengkaji aplikasi algoritma Particle Swarm Optimization (PSO) untuk optimasi bentuk airfoil. Metodologi optimasi meliputi integrasi fungsi bentuk Parsec untuk representasi bentuk airfoil, algoritma swarm sebagai agen pencari dan model ANN untuk perhitungan. PSO diusulkan untuk pengujian dua varian. Hasilnya dipetakan ke grafik yang menunjukkan bahwa model tersebut adaptif dan cocok untuk aplikasi desain airfoil. Model yang diusulkan membutuhkan desain lebih lanjut, pengembangan dan validasi untuk mengurangi persentase kesalahan simulasi.

Suatu optimasi perancangan airfoil menggunakan metode panel pada bilangan Reynold rendah telah dilakukan oleh (Stalewski \& Sznajder, 2010). Sistem persamaan linear dimensi $n+1$ diturunkan dari panel vortex dan source pada permukaan airfoil. Hasil analisis aerodinamis menggunakan XFOIL menunjukkan bahwa koefisien angkat memiliki beberapa peningkatan pada sudut serang kisaran $0-12^{\circ}$. Sehingga dapat disimpulkan bahwa metode panel sangat cocok untuk proses perancangan dan optimasi karena rendahnya biaya komputasi dan kemampuan estimasi aerodinamis pada sudut serang tinggi.

Adapun tujuan dari penelitian ini adalah : 1) melakukan validasi hidrodinamika hidrofoil menggunakan solver XFoil, 2) melakukan analisis hidrodinamika hidrofoil untuk menentukan koefisien gaya angkat (lift) dan hambat (drag), pengaruhnya terhadap thickness, camber serta bilangan Reynold, serta 3) menerapkan metode optimasi Particle Swarm untuk mendapatkan geometri hidrofoil Naca 63(3)018 yang memberikan rasio koefisien gaya angkat dan hambat maksimum $\left(C_{L} / C_{D}\right.$ maks $)$.

\section{METODE PENELITIAN}

Dalam penentuan profil hidrofoil optimum dilakukan melalui tiga tahapan yaitu penentuan foil Naca 63(3)018. Selanjutnya iterasi dengan XFoil solver, dan proses optimasi menggunakan GNU
Octave 4.4.1. Adapun tahapan tersebut dijelaskan sebagai berikut : Pertama penentuan bilangan Reynold yaitu 150,000; 200,000; dan 250,000; serta sudut serang $2^{\circ}, 4^{\circ}, 6^{\circ}, 8^{\circ}$, dan $10^{\circ}$. Sesuai (Williamson et al., 2012) koordinat hidrofoil untuk Naca 63(3)018 sudah diketahui. Selanjutnya, setiap koordinat hidrofoil yang diperoleh dianalisis menggunakan XFoil untuk mendapatkan $C_{L} / C_{D}$ maksimum. Koefisien drag dan rasio lift-drag juga ditampilkan.

Perhitungan selanjutnya adalah menghitung apakah nilai $C_{L} / C_{D}$ sudah maksimum? Apabila sudah maksimum proses berhenti, artinya didapatkan nilai $C_{L} / C_{D}$ maksimum, namun apabila belum maksimum, geometri hidrofoil diupdate dan proses diulang sampai maksimum. Tahap berikutnya adalah proses optimasi menggunakan GNU Octave 4.4.1. Pada proses ini sebagai fungsi obyektif adalah $\mathrm{C}_{\mathrm{L}} / \mathrm{C}_{\mathrm{D}}$ maksimum, sedangkan variabel perancangannya adalah koordinat pada hidrofoil. Untuk lebih jelas tentang tahapan penelitian disajikan dalam Gambar 1 .

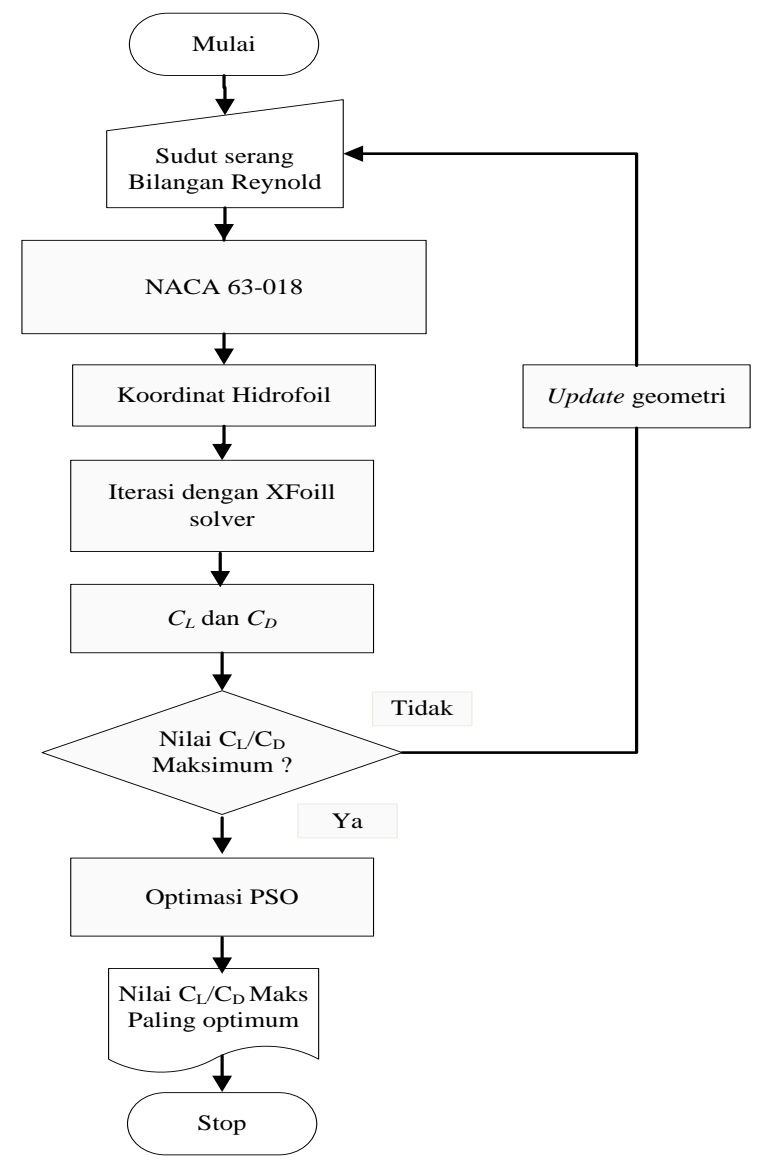

Gambar 1. Tahapan Penelitian

\section{Lokasi Penelitian}

Lokasi penelitian di Laboratorium Komputer Teknik Mesin STT Ronggolawe Cepu. 


\section{Peubah yang diamati/diukur}

Adapun peubah yang diamati adalah profil hidrofoil yang memberikan $\left(C_{L} / C_{D}\right)$ maksimum pada sudut serang dan bilangan Reynold tertentu.

\section{Model yang digunakan}

Model yang digunakan meliputi 2 macam model, yaitu (1) solver menggunakan XFoil untuk mengidentikasi nilai $\mathrm{C}_{\mathrm{L}}$ dan $\mathrm{C}_{\mathrm{D}}$ maksimum, dan (2) model optimasi dengan dan Particle Swarm sebagai penentu profil hidrofoil yang memberikan $\left(C_{L} / C_{D}\right)$ maksimum.

\section{Rancangan Penelitian}

Dalam penentuan profil hidrofoil optimum dilakukan melalui tiga tahapan yaitu penentuan foil yaitu NACA 63(3)-18-il. Iterasi dengan XFoil solver, dan proses optimasi menggunakan Octave 4.4.1 Adapun tahapan tersebut dijelaskan sebagai berikut : Pertama penentuan bilangan Reynold yaitu 150,000; 200,000; dan 250,000; serta sudut serang $2^{\circ}, 4^{\circ}, 6^{\circ}, 8^{\circ}$, dan $10^{\circ}$. Sesuai Williamson, dkk (2012) koordinat hidrofoil untuk NACA 63(3)18-il sudah diketahui. Selanjutnya, setiap koordinat hidrofoil yang diperoleh dianalisis menggunakan XFoil untuk mendapatkan $C_{L} / C_{D}$ maksimum.

Selanjutnya, koefisien drag dan rasio liftdrag juga ditampilkan. Perhitungan selanjutnya adalah menghitung apakah nilai $C_{L} / C_{D}$ sudah maksimum? Apabila sudah maksimum proses berhenti, artinya didapatkan nilai $C_{L} / C_{D}$ maksimum, namun apabila belum maksimum, geometri hidrofoil diupdate dan proses diulang sampai maksimum.

Tahap berikutnya adalah proses optimasi menggunakan Octave 4.4.1. Pada proses ini sebagai fungsi obyektif adalah $\mathrm{C}_{\mathrm{L}} / \mathrm{C}_{\mathrm{D}}$ maksimum, sedangkan variabel perancangannya adalah koordinat pada hidrofoil. Adapun langkah-langkah yang dilakukan untuk mendapatkan hasil optimasi adalah sebagai berikut :

a. Menentukan parameter hidrofoil yang akan dioptimasi.

b. Menentukan persamaan hidrofoil..

c. Menentukan objective function, variabel desain, serta batasan-batasan yang akan digunakan.

d. Menuliskan persamaan objective function dan constraints pada $m$-file.

e. Melakukan optimasi pada Octave 4.4.1.

f. Plot variabel hasil optimasi.

g. Menggambar hidrofoil hasil optimasi.

Pada penelitian ini akan dilakukan proses optimasi dengan variabel desain yang berbedabeda. Hal ini untuk memperlihatkan bahwa optimasi yang dilakukan mendapatkan hasil yang sesuai dengan objective function dan untuk melihat perbedaan nilai $C_{L} / C_{D}$ dengan masing masing variabel desain.
Adapun langkah-langkah optimasi dengan pemrograman Octave 4.4.1 di atas adalah sebagai berikut:

a. Membuka program bantu yang digunakan, yakni Octave 4.4.1, kemudian dipilih File $>$ New $>$ m-file.

b. Memasukkan semua parameter yang diketahui seperti $\alpha$, dan bilangan Reynold ke dalam $m$-file.

c. Menginput persamaan objective function. Simpan atau run $m$-file tersebut.

d. Menentukan nilai constraint, dan menentukan tebakan / perkiraan awal. Selanjutnya masih dalam satu $m$-file dengan constraint tadi, masukkan nilai tebakan awal agar proses optimisasi dapat dijalankan.

e. Proses optimisasi. Setelah memasukkan constraint, masukkan pula fungsi optimasi (Gradient Based Method, Algoritma Genetika dan Particle Swarm Optimization) yang digunakan untuk meminimasi objective function. Selanjutnya menjalankan proses optimisasi dengan menekan run.

f. Setelah hasil optimasi didapat, kemudian dimasukkan pada fungsi panel untuk mendapatkan nilai $C_{L}$ dan $C_{D}$.

g. Selanjutnya plot hasil tersebut kedalam sebuah grafik.

PSO merupakan algoritma berbasis populasi yang mengeksploitasi individu dalam populasi menuju daerah penyelesaian dalam daerah pencarian (Khurana et al., 2009). Dalam PSO populasi disebut dengan swarm, dan individu disebut dengan particle. Tiap partikel berpindah dengan kecepatan yang diadaptasi dari daerah pencarian dan menyimpannya sebagai posisi terbaik yang pernah dicapai. Prosedur PSO dapat dijabarkan dengan langkah-langkah sebagai berikut :

a. Asumsikan bahwa ukuran kelompok (jumlah partikel) adalah $N$. Untuk mengurangi jumlah evaluasi fungsi yang diperlukan untuk menemukan solusi, sebaiknya ukuran $N$ tidak terlalu besar, tetapi juga tidak terlalu kecil, agar ada banyak kemungkinan posisi menuju solusi terbaik atau optimal.

b. Bangkitkan populasi awal $X$ dengan rentang $X^{(B)}$ dan $X^{(A)}$ secara random sehingga didapat $X_{1}, X_{2}$, ..., $X_{N}$. Setelah itu, untuk mudahnya, partikel $j$ dan kecepatannya pada iterasi $i$ dinotasikan sebagai $X^{\left({ }^{(i)} \mathrm{j}\right.}$ dan $V_{j}^{(i)}$. Sehingga partikel-partikel awal ini akan menjadi $X_{1}(0), X_{2}(0) . . X_{N}(0)$. Vektor $X_{j}(0),(j$ $=1,2, \ldots, N$ ) disebut partikel atau vektor koordinat dari partikel. (seperti kromosom dalam algoritma genetika). Evaluasi nilai fungsi tujuan untuk setiap partikel dan nyatakan dengan (1).

$$
f\left[X_{1}(0)\right], f\left[X_{2}(0)\right], \ldots . . f\left[X_{N}(0)\right]
$$

c. Hitung kecepatan dari semua partikel. Semua partikel bergerak menuju titik optimal dengan 
suatu kecepatan. Awalnya semua kecepatan dari partikel diasumsikan sama dengan nol. Set iterasi $i=1$.

d. Pada iterasi ke-i, temukan 2 parameter penting untuk setiap partikel $j$ yaitu:

1) Nilai terbaik sejauh ini dari $X_{j}(i)$ (koordinat partikel $j$ pada iterasi $i$ ) dan nyatakan sebagai $P_{\text {best,j }}$ dengan nilai fungsi obyektif paling rendah (kasus minimasi), $f\left[X_{j}(i)\right]$, yang ditemui sebuah partikel $j$ pada semua iterasi sebelumnya. Nilai terbaik untuk semua partikel $X_{j}(i)$ yang ditemukan sampai iterasi ke-i, Gbest, dengan nilai fungsi tujuan paling kecil/minimum diantara semua partikel untuk semua iterasi sebelumnya, $f\left[X_{j}(i)\right]$.

2) Hitung kecepatan partikel $j$ pada iterasi ke $i$ dengan rumus sebagai berikut:

$$
\begin{aligned}
V_{j}(i)= & V_{j}(i-1)+c_{1} r_{1}\left[P_{\text {best }, j}-x_{j}(i-1)\right]+c_{2} r_{2}\left[G_{\text {best }}-\right. \\
& \left.x_{j}(i-1)\right] \\
& j=1,2,3 \ldots N
\end{aligned}
$$

dimana $c_{1}$ dan $\quad c_{2}$ masing-masing adalah learning rates untuk kemampuan individu (cognitive) dan pengaruh sosial (group), dan $r_{1}$ dan $r_{2}$ bilangan random yang berdistribusi uniforml dalam interval 0 dan 1 . Jadi parameters $c_{1}$ dan $c_{2}$ menunjukkan bobot dari memory (position) sebuah partikel terhadap memory (posisi) dari kelompok (swarm). Nilai dari $c_{1}$ dan $c 2$ biasanya adalah 2 sehingga perkalian $c_{1} r_{1}$ dan $c_{2} r_{2}$ memastikan bahwa partikel-partikel akan mendekati target sekitar setengah selisihnya.

3) Hitung posisi atau koordinat partikel $j$ pada iterasi ke-i dengan cara

$$
\begin{aligned}
& \quad X_{j}(i)=X_{j}(i-1)+V_{j}(i) \\
& j=1,2,3 \ldots N
\end{aligned}
$$

4) Evaluasi nilai fungsi tujuan untuk setiap partikel dan nyatakan sebagai

$$
f\left[X_{1}(i)\right], f\left[X_{2}(i)\right], \ldots . . f\left[X_{N}(i)\right]
$$

Cek apakah solusi yang sekarang sudah konvergen. Jika posisi semua partikel menuju ke satu nilai yang sama, maka ini disebut konvergen. Jika belum konvergen maka langkah $d$ diulang dengan memperbarui iterasi $i=i+1$, dengan cara menghitung nilai baru dari $P$ best,j dan $G$ best. Proses iterasi ini dilanjutkan sampai semua partikel menuju ke satu titik solusi yang sama. Biasanya akan ditentukan dengan kriteria penghentian (stopping criteria), misalnya jumlah selisih solusi sekarang dengan solusi sebelumnya sudah sangat kecil.

\section{HASIL DAN PEMBAHASAN}

\section{Validasi terhadap Eksperimen}

Sebagai bahan validasi digunakan hasil analisis aerodinamika hidrofoil tipe MA409. Simulasi dilakukan dengan mengacu pada hasil eksperimen (Williamson et al., 2012). Gambar 2 dan Gambar 3 menunjukkan grafik $C_{L}$ dan $C_{D}$ terhadap sudut serang pada Airfoil MA409 bilangan Reynold 199825.8.

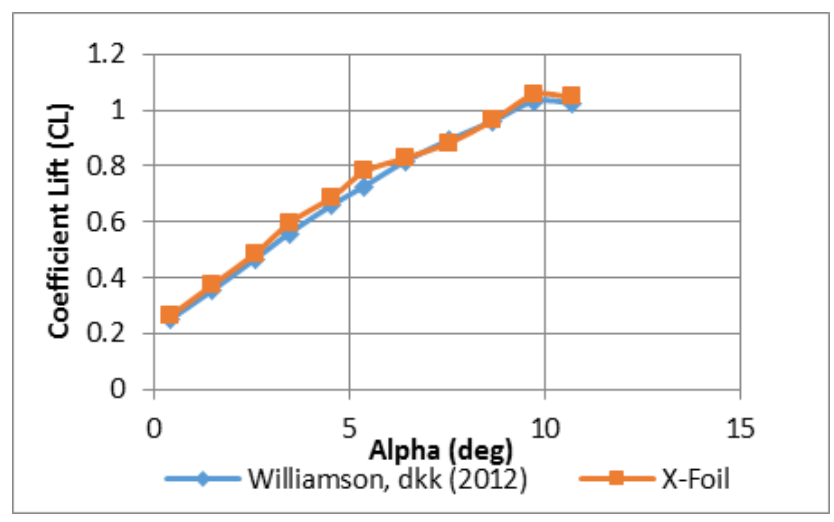

Gambar 2. Grafik validasi $C_{l}$ terhadap sudut serang pada airfoil ma409 bilangan reynold 199825.8

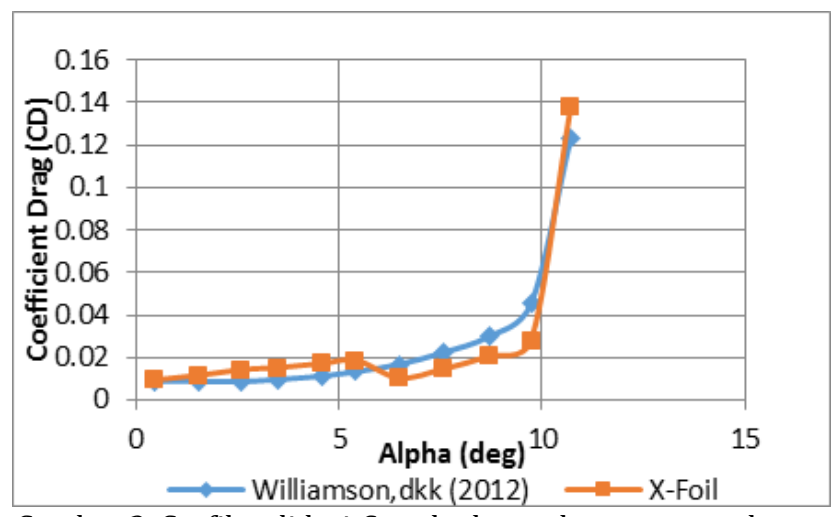

Gambar 3. Grafik validasi $C_{d}$ terhadap sudut serang pada airfoil ma409 bilangan reynold 199825.8

Pada Gambar 2 menunjukkan grafik koefisien lift $\left(C_{L}\right)$ terhadap sudut serang pada airfoil MA409 Bilangan Reynold 199825.8. Validasi ini menghasilkan nilai $C_{L}$ metode panel hampir sama jika dibandingkan dengan hasil eksperimen (Williamson et al., 2012). Stall terjadi pada sudut serang $9.74^{\circ}$, dengan rata-rata kesalahan sebesar $3.65 \%$. Hasil ini dalam toleransi yang diijinkan sesuai literatur (Reid, 2006) yaitu di bawah 9.5\%. Sedangkan Gambar 3 (b) menunjukkan grafik koefisien drag $\left(C_{D}\right)$ terhadap sudut serang pada airfoil MA409 Bilangan Reynold 199825.8. Validasi ini menghasilkan nilai $C_{D}$ metode panel hampir sama jika dibandingkan dengan hasil eksperimen (Williamson et al., 2012). Rata-rata kesalahan sebesar 9.31\%. Hasil ini dalam toleransi yang diijinkan sesuai literatur (Reid, 2006) yaitu di bawah 9.5\%. 
Tabel 1. Nilai $C_{L} / C_{D}$ Optimasi Particle Swarm Optimization (PSO)

\begin{tabular}{rrrrcccc}
\hline Reynold & Alpha & \multicolumn{1}{c}{$\mathrm{X}_{1}$} & \multicolumn{1}{c}{$\mathrm{X}_{2}$} & Fval & $\mathrm{CL}_{\mathrm{L}} \mathrm{opt}$ & $\mathrm{C}_{\mathrm{D}} \mathrm{opt}$ & $\mathrm{C}_{\mathrm{L}} / \mathrm{C}_{\mathrm{D}}$ \\
\hline \multirow{6}{*}{150,000} & 2 & 10.0270 & 1.0081 & $7.63769 \mathrm{E}-06$ & 0.3543 & 0.0030 & 118.1000 \\
& 4 & 9.9201 & 0.9761 & $6.45639 \mathrm{E}-05$ & 0.3820 & 0.0031 & 123.2258 \\
& 6 & 9.9754 & 0.9927 & $2.54980 \mathrm{E}-04$ & 0.4801 & 0.0032 & 149.5437 \\
& 8 & 10.0520 & 1.0156 & $2.75680 \mathrm{E}-05$ & 1.0204 & 0.0058 & 175.9310 \\
& 10 & 9.9574 & 0.9872 & $1.82449 \mathrm{E}-05$ & 1.0724 & 0.0098 & 109.0946 \\
\hline \multirow{6}{*}{00,000} & 2 & 1.0026 & 1.0077 & $9.61800 \mathrm{E}-05$ & 0.4560 & 0.0035 & 129.3617 \\
& 4 & 1.0129 & 1.0392 & $2.48424 \mathrm{E}-04$ & 0.4780 & 0.0026 & 185.2641 \\
& 6 & 0.9647 & 0.8975 & $1.25674 \mathrm{E}-03$ & 0.4805 & 0.0028 & 171.2072 \\
& 8 & 0.9819 & 0.9463 & $4.72200 \mathrm{E}-04$ & 1.1350 & 0.0060 & 189.7993 \\
250,000 & 10 & 1.0007 & 1.0021 & $5.07437 \mathrm{E}-05$ & 1.0145 & 0.0090 & 112.6721 \\
& 2 & 1.0006 & 1.0018 & $1.75570 \mathrm{E}-05$ & 0.3525 & 0.0021 & 167.8571 \\
& 4 & 0.9998 & 0.9999 & $8.63218 \mathrm{E}-06$ & 0.4801 & 0.0022 & 218.2273 \\
& 6 & 1.0016 & 1.0048 & $4.28624 \mathrm{E}-06$ & 0.5807 & 0.0027 & 214.2578 \\
& 8 & 1.0035 & 1.0106 & $4.59876 \mathrm{E}-05$ & 1.0198 & 0.0047 & 216.9787 \\
\hline
\end{tabular}

\section{Optimasi}

Pada penelitian ini optimasi dilakukan pada airfoil Naca 63(3)018 dengan menggunakan metode Particle Swarm Optimization (PSO). Hidrofoil tersebut akan dioptimasi pada tiga bilangan Reynold yaitu 150,000; 200,000; dan 250,000 serta pada lima sudut serang yang mewakili sudut serang rendah yaitu $2^{\circ}$ dan $4^{\circ}$, sedang yaitu $6^{\circ}$ dan $8^{\circ}$, serta tinggi yaitu $10^{\circ}$. Masalah optimasi pada penelitian ini diformulasikan sebagai berikut :

$$
\min f(x)=\min \left(-\frac{C_{L}}{C_{D}}\right)_{\max }
$$

Pada Tabel 1 ditampilkan $C_{L} / C_{D}$ hasil optimasi PSO Hidrofoil Naca 63(3)018 il. Pada tabel 1. terlihat bahwa pada bilangan Reynold yang sama, harga $C_{L}$ semakin besar seiring dengan semakin meningkatnya sudut serang. Seiring dengan kenaikan sudut serang, aliran udara cenderung mengalami separasi (pemisahan) pada permukaan hidrofoil, sehingga terbentuk wake (ulakan) di belakang hidrofoil. Terjadinya separasi aliran ini menyebabkan berkurangnya lift dan meningkatnya drag. Berikut ditampilkan grafik $C_{L} / C_{D}$ - sudut serang hasil optimasi Optimasi Particle Swarm (PSO) pada Naca 63(3) 018 il

Pada Gambar 4 dengan semakin bertambahnya bilangan Reynold maka nilai $C_{L} / C_{D}$ maksimum akan semakin tinggi. Hal ini dikarenakan dengan makin bertambahnya bilangan Reynold maka kecepatan aliran juga makin tinggi sehingga energi yang dibutuhkan pun juga semakin tinggi sehingga akan terjadi penundaan separasi daerah aliran. Penundaan ini akan meningkatkan koefisien lift. Dengan menggunakan metode Particle Swarm bilangan Reynold naik maka nilai maksimum camber cenderung naik dan nilai $\left(C_{L} / C_{D}\right)$ maksimum akan tetap naik. Hal ini dikarenakan dengan makin bertambahnya bilangan Reynold maka kecepatan aliran juga makin tinggi sehingga energi yang dibutuhkan pun juga semakin tinggi sehingga akan terjadi penundaan separasi daerah aliran. Penundaan ini akan meningkatkan koefisien lift. Dengan menggunakan metode Particle Swarm Optimization (PSO), bilangan Reynold naik maka nilai maksimum camber cenderung naik dan nilai $\left(C_{L} / C_{D}\right)$ maksimum akan tetap naik.

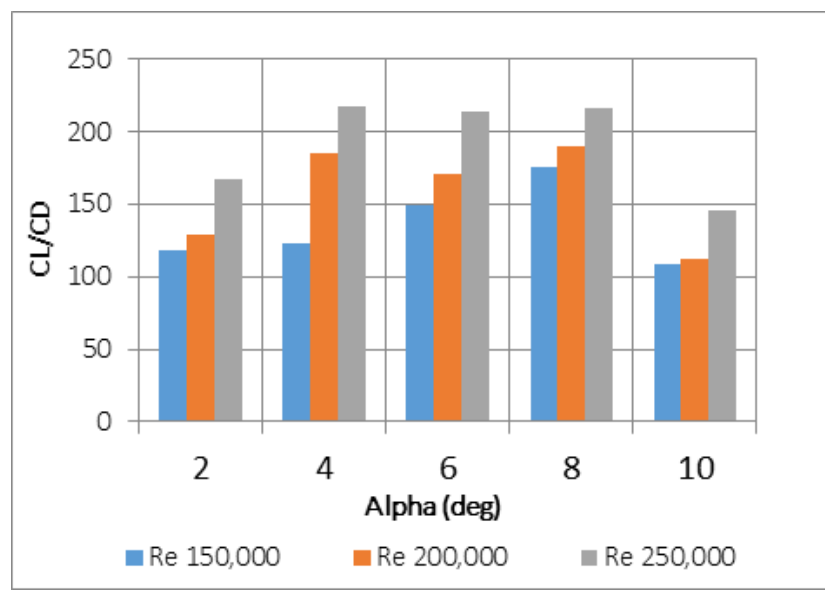

Gambar 4 Grafik $C_{L} / C_{D}$ - Sudut Serang Hasil Optimasi Particle Swarm (PSO) pada Naca 63(3) 018

Selanjutnya geometri airfoil Naca 63(3)018 hasil optimasi Particle Swarm Optimization ditampilkan dalam Gambar 5 sampai Gambar 9.

\section{PENUTUP}

Adapun kesimpulan yang dapat diperoleh dari penelitian ini adalah : Validasi pada Naca 2415 menghasilkan nilai $C_{\mathrm{L}}$ metode panel yang cukup baik dan akurat dengan rata-rata kesalahan sebesar $1.47 \%$, sedangkan validasi untuk $C_{D}$ ratarata kesalahan $1.47 \%$. Sedangkan validasi pada S9000 menghasilkan nilai $C_{\mathrm{L}}$ dengan rata-rata kesalahan sebesar $3.66 \%$, dan $C_{\mathrm{D}}$ dengan rata-rata kesalahan sebesar $6.83 \%$. Sedangkan nilai rasio gaya angkat terhadap gaya hambat $\left(C_{\mathrm{L}} / C_{\mathrm{D}}\right)$ maksimum dipengaruhi oleh bilangan Reynold. Semakin besar bilangan Reynold maka nilai $C_{L} / C_{D}$ maksimum juga semakin tinggi. Selanjutnya 
ketebalan (thickness) dan camber maksimum hidrofoil setelah dioptimasi mempunyai kecenderungan semakin meningkat dengan peningkatan bilangan Reynold.

\section{UCAPAN TERIMA KASIH}

Pada kegiatan penilitian ini penulis menyampaikan terima kasih kepada :

1. DIKTI melalui hibah Penelitian Dosen Pemula sehingga penulis mempunyai kesempatan untuk menyumbangkan pemikirannya.

2. Sekolah Tinggi Teknologi Ronggolawe Cepu, Laboratorium Komputer, para staf, laboran, toolman, yang telah memberikan waktu, sehingga pemrograman dan olah data bisa dilaksanakan

\section{DAFTAR PUSTAKA}

Abbott, I. H., \& Von Doenhoff, A. E. (1959). Theory of wing sections, including a summary of airfoil data. Courier Corporation.

Acosta, A. J. (1973). Hydrofoils and hydrofoil craft. Annual Review of Fluid Mechanics, 5(1), 161184.

Hepperle, M. (2011). Xfoil User's Guide. December.

Karim, M. M., Suzuki, K., \& Kai, H. (2004). Optimal design of hydrofoil and marine propeller using micro-genetic algorithm $(\mu \mathrm{GA})$. Journal of Naval Architecture and Marine Engineering, 1(1), 47-61.

Katz, J., \& Plotkin, A. (2001). Low-speed aerodynamics (Vol. 13). Cambridge university press.

Khurana, M., Winarto, H., \& Sinha, A. (2009). Airfoil optimisation by swarm algorithm with mutation and artificial neural networks. In 47th AIAA Aerospace Sciences Meeting including the New Horizons Forum and Aerospace Exposition (p. 1278).
Marzocca, P. (2017). The NACA Airfoil Series. Retrieved from http://people.clarkson.edu/

Ouyang, H., Weber, L. J., \& Odgaard, A. J. (2006). Design optimization of a two-dimensional hydrofoil by applying a genetic algorithm. Engineering Optimization, 38(5), 529-540.

Reid, M. (2006). Thin/cambered/reflexed airfoil development for micro-air vehicles at Reynolds numbers of 60,000 to 150,000 .

Selig, M. S., \& Guglielmo, J. J. (1997). High-lift low Reynolds number airfoil design. Journal of Aircraft, 34(1), 72-79.

Stalewski, W., \& Sznajder, J. (2010). Application of a panel method with viscous-in-viscid interaction for the determination of aerodynamic characteristics of Cesar BaseLine aircraft. Prace Instytutu Lotnictwa, 7697.

Suryadi, A., Arief, I. S., \& Amiadji, A. (2017). Analisa Pengaruh Sudut Serang Hidrofoil Terhadap Gaya Angkat Kapal Trimaran Hidrofoil. Jurnal Teknik ITS, 5(2).

Williamson, G. A., McGranahan, B. D., Broughton, B. A., Deters, R. W., Brandt, J. B., \& Selig, M. S. (2012). Summary of low-speed airfoil data. University of Illinois Low Speed Airfoil Tests.

Zhang, F., Chen, S., \& Khalid, M. (2002). Optimizations of airfoil and wing using genetic algorithm. In 23rd Congress of International Council of the Aeronautical Sciences, Toronto, Canada. 


\section{LAMPIRAN}
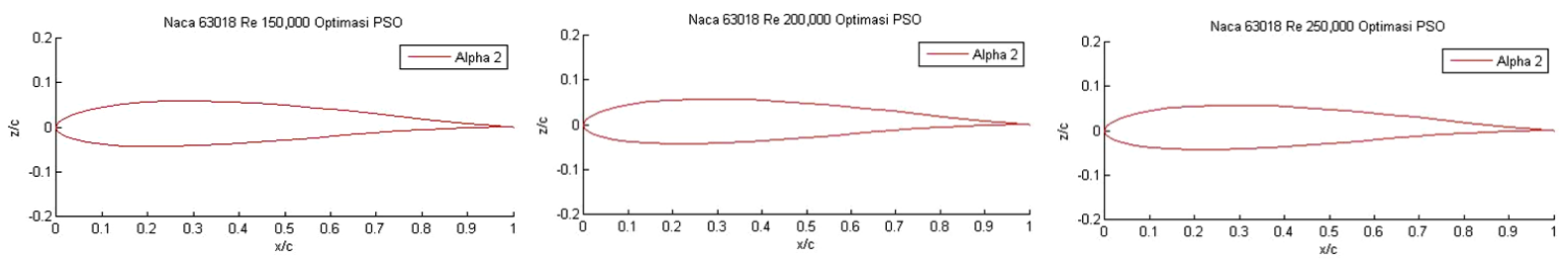

Gambar 5 Geometri Naca 63(3)018 Optimasi PSO Sudut Serang $2^{\circ}$
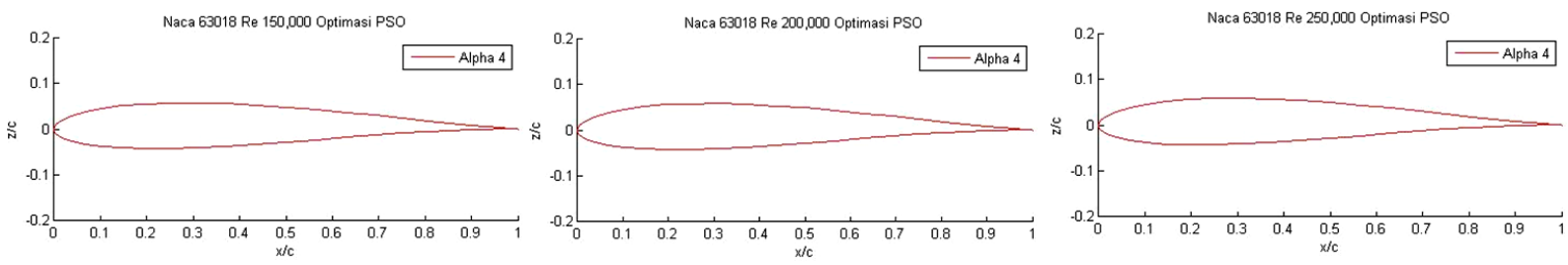

Gambar 6 Geometri Naca 63(3)018 Optimasi PSO Sudut Serang $4^{\circ}$
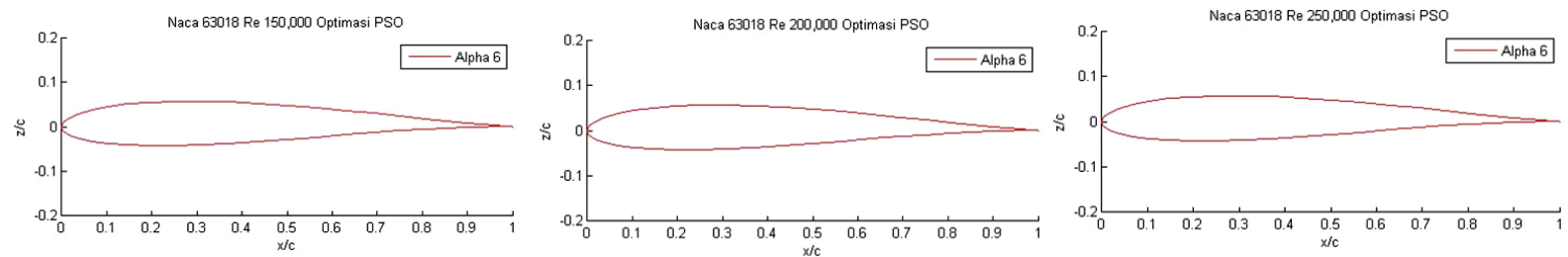

Gambar 7 Geometri Naca 63(3)018 Optimasi PSO Sudut Serang $6^{\circ}$
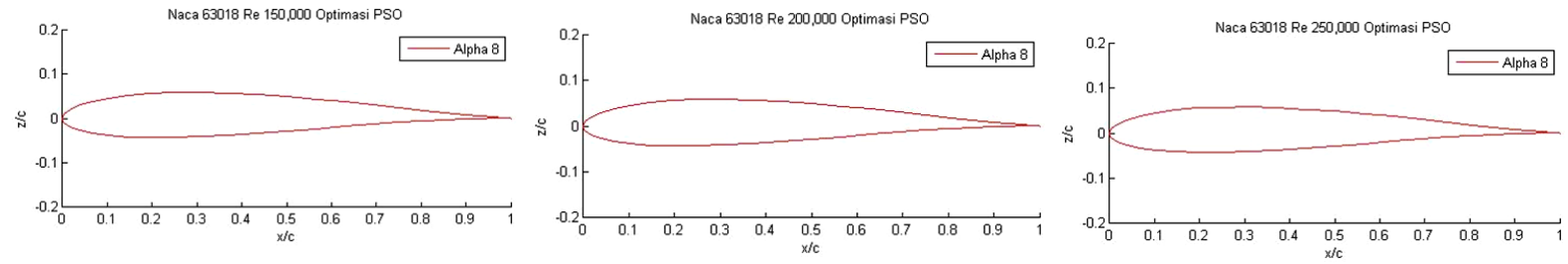

Gambar 8 Geometri Naca 63(3)018 Optimasi PSO Sudut Serang $8^{\circ}$
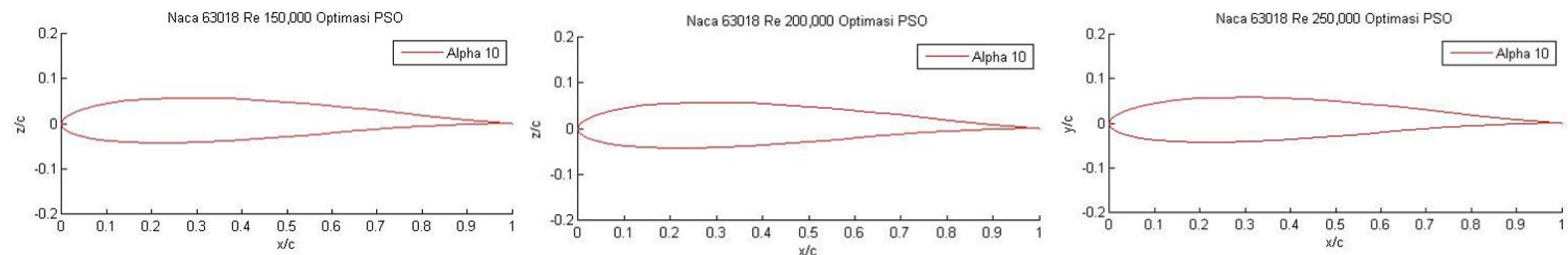

Gambar 9 Geometri Naca 63(3)018 Optimasi PSO Sudut Serang 10 
E H Herrapraastanti, dkk / Teknika : Engineering and Sains Journal, Vol. 2, No.2, Desember 2018, 79-86

Halaman ini sengaja dikosongkan 